\title{
Attitudes of healthcare professionals and the public towards the sale of kidneys for transplantation
}

\author{
Astrid Guttmann and Ronald D Guttmann McGill University, Canada
}

\section{Authors' abstract}

We conducted a survey of attitudes towards the sale of kidneys for transplantation within and without the medical community. Half of those polled received a case of a young man in India whose only chance for survival was to purchase a kidney, the other half a case of a Canadian man who was suffering side-effects from dialysis and had been on the transplant waiting list for three years. We found the percentage of responses allowing the patients to purchase a kidney was similar for the two cases (40 per cent in the Canadian case and 49 per cent in the Indian case). The medical groups had much lower rates of approval of this practice than the public. In all groups those allowing the practice showed similar concerns about regulation. This survey indicates public opinion to be contrary to public policy.

\section{Introduction}

With the advent of potent immunosuppressive drugs for renal transplantation, the scope of potential living kidney donations to patients with endstage renal disease (ESRD) has widened. In most countries with transplant programmes, this practice has been confined to donors related, either genetically or in some cases emotionally, to the recipient. The transplant community has voiced concerns about this practice, centring mainly around the issue of risk to the donor (estimated at one donor death per 1600 nephrectomies) (1) and possible coercion of the donor. However, this practice exists (at the present time, approximately 15 per cent of all kidneys transplanted in North America stem from living donors) $(2,3)$ and is sanctioned by the international transplant organizations. In contrast, the international transplant community has roundly condemned the practice of living unrelated donation which involves payment of the donor (4, 5). All western nations have laws banning the sale of organs and tissues. Some of these laws are of

\section{Key words}

Live donor transplantation; kidney transplant commercialism; attitude survey on selling kidneys. older origin, adopted to protect against the commercialization of other organs, as in Italy, whereas other nations, such as Great Britain, passed the law in response to incidents of sale of kidneys for transplantation.

Yet the practice of paid, unrelated donation is flourishing in a number of developing countries, such as Brazil, Egypt and India where endemic poverty ensures vast numbers of willing donors and existing laws provide no guidelines for the practice $(6,7)$. In a country such as India, where there is no cadaveric transplant programme and very little dialysis available (the most optimistic estimates cite 18,000 patients with access to dialysis per year, in contrast to the 80,000 new cases of renal failure peto year) (8), living donation is the only option for? survival. For those with no suitable relatives, unrelated donation is the only possibility. This type of transplantation has taken many forms - from programmes in which the doctors match donor and recipient with good medical results, to much less professional scenarios with unscrupulous middlemen, 'organ brokers', haunting impoverished towns, with high donor and recipient mortality (9). The reaction of the western medical establishment to reports of this practice was swift condemnation. However, within the Indian transplant community there exists no monolith of opinion. Some of the physicians see this practice as providing a service to both the recipient and the donor, and as the only alternative until a cadaveric programme can be established (10). Others see the practice as unethical, unregulatable and a hindrance to the development of a cadaveric programme (11). The Indian doctors are, however, unanimous in their condemnation of the western reaction, as being formulated in the vacuum of the reality of the situation in India.

At present, most decisions concerning the sale of organs both abroad and at home have been taken by the transplant community and the government. In light of the Indian practice and the strong western reaction against it we were interested in hearing the voice of the general public. We decided to undertake an attitude survey on the sale of kidneys for transplantation within and without the medical community. We chose to poll the general public, first-year 
medical students, non-transplant physicians and nurses, and transplant physicians and nurses to see if any marked differences in attitude exist among the groups. We used both a Canadian and an Indian medical-case scenario to determine whether the response was any different in a situation in which the sale of a kidney was the only option for survival, as in India, versus one in which long-term dialysis and the possibility of eventual cadaveric donation was available. By so doing, we sought to establish whether people's beliefs about the sale of organs are dependent on a given set of circumstances, or whether they are dictated by a set of universal ethical principles. Since the official stance on the practice bans it, we were interested in the responses of those who favour the legalization of the practice, and thus asked them for the factors that were important in their decision.

\section{Methods}

We administered equal numbers of two different questionnaires (see appendices 1 and 2), one per person, to 100 first-year medical students at McGill University, to 150 members of the general public (via door-to-door solicitation) and to 137 physicians and 94 nurses of whom 28 and 34 are transplant doctors and nurses/technicians respectively. The medical staff all work in hospitals affiliated with McGill University Faculty of Medicine, many of them being from the Royal Victoria Hospital. A covering letter accompanied the questionnaire, explaining its purpose and assuring confidentiality. However, we did not reveal that there were two different questionnaires.

Both questionnaires consisted of a brief description of a 32-year-old man suffering from renal failure, one near Montreal, Canada (appendix 1) and the other in Madras, India (appendix 2). Both wanted a transplant, neither had relatives suitable for living related donation. The Canadian, David, was on dialysis and could remain so indefinitely and was on the waiting list for a cadaveric donation. He was suffering from progressive neuropathy as a side-effect of the dialysis. Varun, an Indian, did not have the possibility of permanent dialysis, nor of a cadaveric donation. In both scenarios the possibility of buying a kidney from a living donor is presented. The first question asked whether paying donors for kidneys is legal in Quebec (David) or India (Varun). The second question asked whether such a practice should be allowed, regardless of the present legal status. If the respondents answered 'no' they were finished with the survey. If they responded affirmatively other questions followed, 24 in the case of David, 22 in the case of Varun, some with subquestions, to determine which conditions were important in the respondent's decision. These factors ranged from details of the recipient's age, profession and ability to pay; the donor's health, nationality and reason for needing the money earned with the sale, to issues of regulation and funding. The questions were almost identical for the two questionnaires with the exception of two supplemental questions for David's case which dealt with aspects of his dialysis not applicable in Varun's case. All respondents were then asked to supply their age, profession and gender and to indicate whether they were professionally involved with transplantation or were personally acquainted with a renal transplant recipient. A space was provided at the end of the survey for additional comments.

A statistical analysis was performed using the SAS statistical package. A chi square test for statistical significance was done for each question. Twentyone of the surveys were omitted from analysis for reasons of incompleteness (if more than four questions were left unanswered), or in the case of one $\vec{\omega}$ from the public sample because of the psychotic $\dot{\omega}$ nature of the comments at the end of the survey.

\section{Results}

We received responses from 70 (47 per cent) of the public $(\mathrm{Pu})$ of which seven were rejected, from 89 (89 per cent) of the first-year medical students (MS), from 117 (69 per cent) of the physicians and nurses (Med), of which 13 were rejected, and from 46 (74 per cent) of the transplant doctors, nurses and technicians ( $\mathrm{Tx}$ ), of which one was rejectes Given the length and the complexity of the subjeci matter of the survey, we considered the overaft response rate to be reasonable. The response rate of the public, while lower than that of the medical students and healthcare professionals, was still high enough to provide an overall picture of attitudes. The biographical information (including personal knowledge of, or relationship to, a kidney donor or recipient) provided by the respondents did not indicate any obvious bias common to those who responded from the public. However, as with any survey, it is impossible to eliminate the possibility of response/non-response bias.

\section{SHOULD DAVID AND VARUN BE ALLOWED TO BUY A KIDNEY?}

The total percentage of responses sanctioning the $\frac{D}{O}$ purchase of a kidney was remarkably similar for Varun and David (see Table 1). Forty-nine per cent 0 of all respondents to the Indian case would find the sale permissible, whereas in the Canadian case 40 per cent would. There was however, a marked difference between the groups on the issue. The public answered 'yes' at rates of 69 and 74 per cent for David and Varun respectively. Medical students answered 'yes' at rates of 51 and 57 per cent for David and Varun respectively, whereas only 23 per cent (in the case of David) and 27 per cent (in the case of Varun) of the doctors and nurses answered affirmatively. While only 21 per cent of the transplant community would sanction David's purchase, 43 per cent would sanction that of Varun. For each 
of the groups there was a slightly higher ( 6 per cent or less) rate of approval of a sale of a kidney in Varun's case, with the exception of the transplant group which had a 22 per cent higher rate of approval of the practice in Varun's case. There was no significant difference in response along the lines of the gender of the respondents.

On the question of the legal status of the sale of kidneys in Quebec and India it is interesting to note that 30 per cent of the medical group and 17 per cent of the transplant group did not know whether the sale of kidneys was legal in Quebec. Sixty-nine per cent of the public were unsure of the legality of the practice. Although 56 per cent of the medical students were unsure of the legal status in Quebec, fewer students than members of the medical group thought it legal practice ( 2 per cent versus 4 per cent). Most respondents to the Indian scenario were unsure of the legal status, but 14 per cent of the transplant group, 8 per cent of the medical group, 9 per cent of the medical students and 6 per cent of the public knew that it was not an illegal practice.

\section{THE MOST IMPORTANT FACTORS IN ALLOWING THE} SALE OF KIDNEYS

There was considerable unanimity between the groups as to which factors were important in their decision to allow the sale of a kidney for both cases (see Table 2). The following were considered important by over 70 per cent of all respondents: severity of the recipient's condition; uncertainty of receiving a kidney from a cadaver; impossibility of receiving dialysis for Varun and the side-effects of dialysis for David; health of the donor and the medical risk to the donor; who obtained consent and the circumstances under which it was obtained; the way in which the sale was arranged, of which a majority were in favour of the transplant hospital or a not-for-profit agency arranging the sale and not in favour of a for-profit organization doing so. There was less consensus as to whether the recipient, the doctors or the government should be able to initiate the sale. About half the respondents would allow the donor to initiate the sale in the Canadian context, but fewer than one third would want the Indian donor to be able to initiate the sale.

A large majority of the respondents thought it important that there be institutions regulating the practice. The overwhelming majority were not in favour of commercial boards such as the Montreal or Madras Board of Trade being involved in the regulation. The majority found professional health organizations, hospital organizations, the government and an international medical institution such as the World Health Organization (WHO) to be acceptable institutions for regulation.

How the price of the kidney should be determined was also deemed important by over 70 per cent of the respondents. Over 70 per cent did not want the transplant doctors, nor free-market mechanisms to be part of the pricing mechanism. Over 60 per cent did not want the hospital involved, and about the same number would like the government involved. About half wanted the price to be a private decision between donor and recipient.

FACTORS NOT CONSIDERED IMPORTANT IN THE DECISION TO ALLOW THE SALE OF KIDNEYS

The factors deemed by over 70 per cent of the respondents not to be important all related to the donor: his nationality, profession, his relationship to the recipient, his economic status and the reason that he needed the money (see Table 3). It is interesting to note that although many respondents used the last section of the questionnaire to voice concerns that a system of sale of kidneys would risk exploiting the poor, very few thought that the donor's economic status should affect his ability to donate.

\section{ECONOMIC CONSIDERATIONS}

\section{1) Ability of the recipient to pay}

The ability of the recipient to pay was given different importance by the four groups and varied between the two cases. For David's case, only 27 per cent of the public and 36 per cent of the medical students considered his ability to pay to be a factor in their decision. By contrast 69 per cent of the medical group and 60 per cent of the transplant group considered this a factor. The trend was reversed for Varun's case. Fifty-two per cent of the public and 42 per cent of the medical students considered Varun's ability to pay important, whereas only 31 per cent of the medical group and 11 per cent of the transplant group thought his ability to pay important.

\section{2) Role of the healthcare system in financing}

Respondents were asked whether the Canadian and Indian healthcare systems should pay the kidney donor fee and for the transplant. These two questions were the most frequently omitted, especially in the Indian case. Many commented on the side that they did not know enough about the Indian healthcare system to respond. The public thought similarly for the two cases: about half thought that Quebec Medicare and the Indian healthcare system should pay the fee; the medical and transplant groups being more in favour of the Indian system paying the donor fee than the Canadian. Medical students diverged more between the two cases - 36 per cent thought that David's donor fee should be paid for while 70 per cent thought that Varun's fee should be paid. In all four groups more than three-quarters responded that the two systems should pay for the transplant.

\section{Comments}

Many of the comments of those responding both in the affirmative and the negative to the question of the sale of kidneys voiced concerns over the exploitative nature of such a system, in which inevitably the 


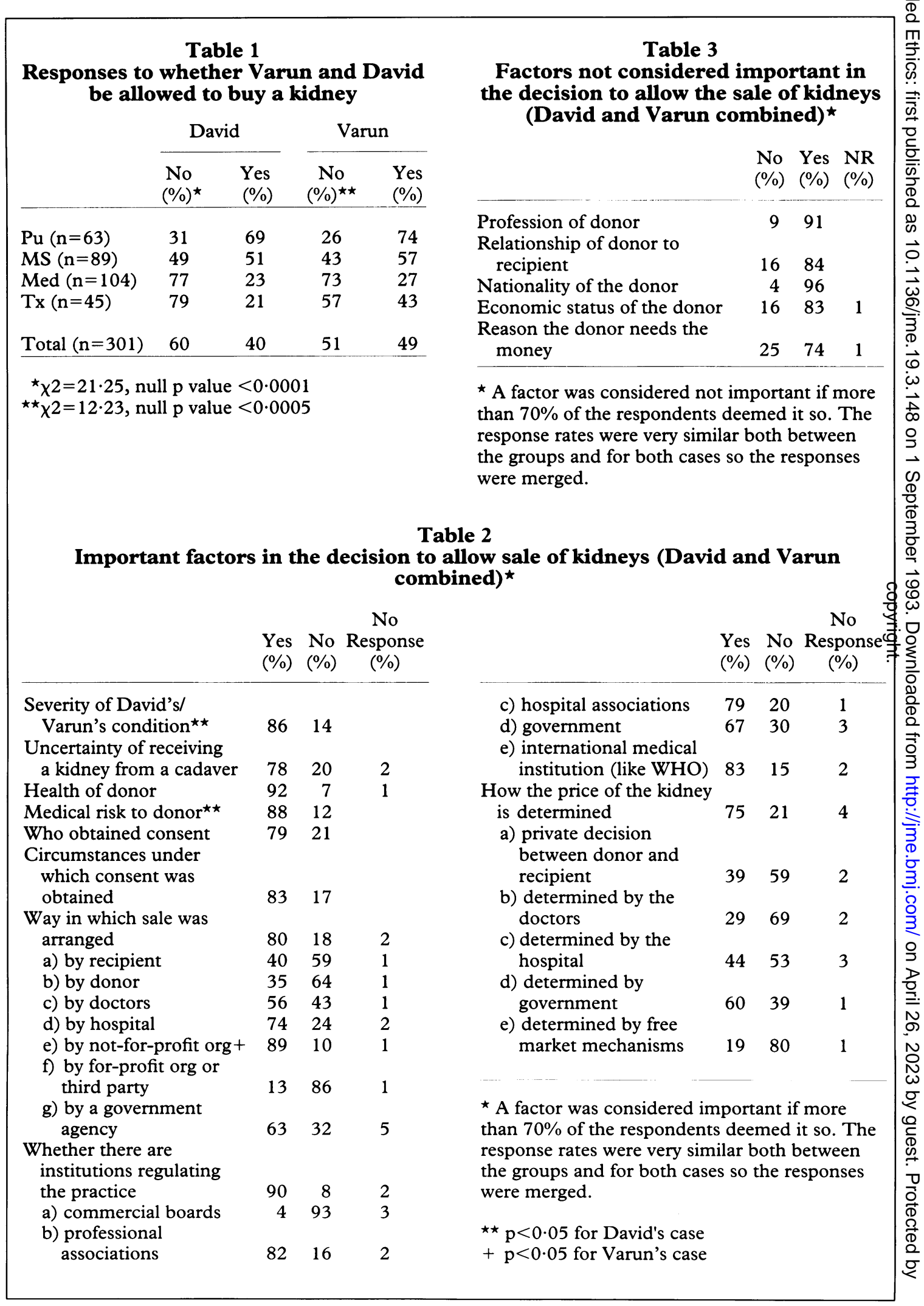


poor would donate and the affluent would receive. However, many also acknowledged the benefits for both sides; according to one respondent: 'there is a fine line between compassion and exploitation'. Many of those who had answered in the affirmative also stressed the need for tight regulation of such a practice. Most acknowledged the difficulty in resolving the issue, although a few of those who would not allow such a practice used very strong language to describe their reaction. One likened the practice to 'slavery', another to 'cannibalism'.

\section{Discussion}

The results of this survey point to some interesting observations. The first is that although Varun in the Indian case was presented with no alternative but death unless allowed to buy a kidney, only slightly higher numbers of respondents would allow him to buy one than David. The members of the transplant group were an exception, with twice as many sanctioning the practice in Varun's case as in David's. This would imply that the decision not to allow the sale is based less on the mitigating factors of the circumstances surrounding the case - for what could be a more severe choice than the one facing Varun than on ethical principles. In the literature, many of those who oppose the practice do so not out of any absolute ethical principles but out of a belief that this practice cannot be regulated (12). However, in our survey respondents were asked whether this practice 'ever be allowed', so presumably that group would answer in the affirmative and then list the conditions of regulation that were important.

Just as those who would not allow the practice did so no matter what the circumstances, those who would allow such a practice would do so only under certain circumstances. There were factors, across all groups polled, that were deemed important. The majority cited the severity of the patient's medical condition as a factor (although the severity was different in the two cases), as well as the health of and risk to the donor. There was a clear concern that the practice be strictly regulated. The majority were not in favour of the options which involved 'pure' commercialism: commercial advertising, commercial boards regulating the practice, and free-market mechanisms determining the price. Involvement of non-profit organizations, hospitals and organizations such as the World Health Organization were preferred. Further regulation involved who should obtain consent and how it should be done. However, respondents did allow certain facets of this practice to stand outside of regulation. They did not consider the reason that the donor needed the money, nor the relationship between the donor and recipient to be important factors. Furthermore, 59 per cent of all respondents thought that the setting of the price of the kidney should be a private decision between donor and patient.
The sensitivity of the respondents to potential abuses in the system is joined with a concern that the practice be universally available, in particular in the Indian case. Varun's ability to pay was not considered important by 61 per cent of all respondents, and about the same number thought that the Indian healthcare system should pay the donor fee. Seventy-three per cent of the public thought that David's ability to pay should not be a factor, but the medical and transplant groups were less generous. It is interesting to note that the cost-effectiveness of a kidney transplant versus long-term dialysis means that this reaction on the part of the healthcare establishment cannot be explained in terms of a costbenefit type of analysis.

The main difference between the groups, however, lies in the percentage of each which would allow the practice to occur. The two groups of healthcare professionals had much lower rates of affirmation of this practice than the general public and medical students for both cases. Assuming that this difference is due to a more informed perspective, this begs the important question of what the members of these two groups know that the public and medical students do not. This is an important question for many reasons. Although there is legislation against this practice in the western nations and western professional condemnation of it in developing countries, the issue will no doubt resurface. The reported dissatisfaction of Indian professionals with the manner in which their health policies have been judged by the west will make a reassessment of the situation necessary. The results of this survey should support this action. There is no overwhelming mandate from our results, either from the public or even from the healthcare professionals, especially the transplant group, to indicate that the issue is resolved. Furthermore, in our own society these issues lie in the not-so-distant future. The numbers on the waiting lists are increasing, and the high costs of technology such as dialysis will force the issue into the political arena. There have already been many proposals by economists and lawyers for 'futures markets' for cadaveric donation $(13,14)$ to decrease the numbers of patients on waiting lists. Surely the sale of kidneys and other organs is not such a leap of logic from such proposals.

The debate should be welcomed for many reasons. Our survey clearly shows that there is no clear consensus on this issue. Whatever reasons account for the differences in attitude between the healthcare profession and the public must be made known. If this practice is to be banned, then the reasoning behind the prohibition must be formulated and debated in the public arena. This debate will touch on some of our most culturally sensitive issues - such as those of the sanctity of the body versus the sanctity of life - as well as more pragmatic issues of resource allocation and individual rights. The sale of kidneys for transplantation is only one of many practices that challenge these issues. 


\section{Acknowledgement}

We thank Dr Jaime Caro and Suzanne Wait for assistance with the statistical analysis and Mrs Sharon MacMillan for secretarial skilfulness.

Astrid Guttmann, MSc, is a Summer scholarship medical student in the Centre for Clinical Immunobiology and Transplantation, McGill University, Montreal, Quebec, Canada. Ronald D Guttmann, MD, is Director and Professor in the same centre.

\section{References}

(1) Bay W H et al. The living donor in kidney transplantation. Annals of internal medicine 1987; 106: 719-727.

(2) Canadian organ replacement register, 1989: annual report. Hospital medical records. Don Mills, Ontario: 1991.

(3) Terasaki P I, ed. Clinical transplantation 1990. Los Angeles: UCLA Tissue Typing Laboratory, 1990.

(4) World Health Organization. Guiding principles on human organ transplantation. Lancet 1991; 337: 1470-1471.

(5) The council of the Transplantation Society. Commercialization in transplantation: the problems and some guidelines to practice. Lancet 1985; 2 : 715-716.

(6) Hedges C. Egypt's desperate trade: body parts for sale. New York Times 1991 Sept 23: A1 + A8.

(7) Pampadi $\mathrm{K}$ et al. Poaching on the poor. The week 1987 Mar 8-14: 16-21.

(8) Reddy K C et al. Unconventional renal transplantation in India. Transplantation proceedings 1990; 22, 3: 910-911.

(9) Salahudeen A K et al. High morality among recipients of bought living-unrelated donor kidneys. Lancet 1990; 336: 725-728.

(10) Reddy K C. Organ donation for consideration: an Indian viewpoint. In: Land W, Dossetor JB, eds. Organ replacement therapy: ethics, justice, commerce. Heidelberg: Springer-Verlag, 1991.

(11) Chengappa R. The organs bazaar. India today 1990 Jul 31: 60-67.

(12) Abouna G M et al. The negative impact of paid organ donation. See reference (10).

(13) Blair R D, Kaserman D L. The economics and ethics of alternative cadaveric organ procurement policies. Yale journal on regulation 1991; 453, 8: 403-452.

(14) Cohen L. Increasing the supply of transplant organs: the virtues of a futures market. George Washington law review 1989; 58, 1: 1-51.

\section{Appendix 1}

David $\mathrm{R}$ is a 32-year-old store manager who lives in Hudson. $\mathrm{He}$ is married and has two young children. Three years ago, he was diagnosed with chronic kidney failure - he has been on dialysis ever since. He must drive $40 \mathrm{~km}$ to reach the hospital, where he is dialysed three times per week for five hours at a time. He functions adequately at work, but suffers some fatigue. Recently, he has developed progressive nerve damage and muscle dysfunction related to the kidney failure, which interferes with walking. His doctors agree that the quality of his life and the nerve damage will improve with a successful and immediate kidney transplant. He has wanted one and has been on the waiting list for nearly three years. It is impossible to predict when, if ever, he will be matched to receive a cadaveric donor kidney. There are no possible family donors - he is an only child and his only living parent suffers from severe, high blood pressure, thus precluding potential living related kidney donation.

David has heard that he can obtain a kidney for $\$ 25,000$. It will come from a healthy, adult living donor, who will sell for a fee.

\section{Appendix 2}

Varun $M$ is a 32-year-old store manager who lives in Madras, India. $\mathrm{He}$ is married and has two young children. Six weeks ago, he was diagnosed with end-stage kidney disease. $\mathrm{He}$ has been told that he can receive temporary peritoneal dialysis, but permanent dialysis is not available. His only chance for survival is a kidney transplant. For cultural, financial and logistical reasons, cadaveric organ donations are extremely rare in India. There are no possible family donors - he is an only child and his only living parent suffers from high blood pressure, thus precluding potential donation.

Varun has heard that he can obtain a kidney for the Rupee equivalent of $\$ 5,000$. It will come from a healthy, adult living donor. 